\title{
ReneWABle EnERgy SOURCES: Traditional And Modern Age TeCHNOLOGIES
}

\author{
Reza Hafezi ${ }^{a}{ }^{*}$, Mohammad Alipour ${ }^{b, c}$ \\ ${ }^{a}$ Futures Studies Research Group, National Research Institute for Science Policy (NRISP), Tehran, Iran. Email: \\ hafezi@nrisp.ac.ir \\ ${ }^{b}$ School of Engineering and Built Environment, Griffith University, Southport, QLD 4222 Australia. Email: \\ mohammad.alipour@griffithuni.edu.au
}

${ }^{C}$ Cities Research Institute, Griffith University, Southport, QLD 4222 Australia.

* Corresponding author: hafezi@nrisp.ac.ir (Reza Hafezi)

\section{Definition:}

Renewable energy (RE) resources are those energy types that are replaced by natural processes over time. However, the noted definition is not complete. After the Industrial Revolution, the rate of energy resources utilization jumped, and as an example annual per capita energy consumption increased by about $170 \%$ during 1750's to 1850's in England (Wrigley 2010). As a result, the definition of a RE resource has evolved to incorporate the replacing period, such that the consumption rate of a RE should be slower than the rate of which nature can replace them, unless the gap can be filled by human activities.

\section{Introduction:}

The primary RE resource embedded non-RE sources, such as oil and minerals, which take millions of years to reform in the earth. Then earth can replace non-RE resources but at a meager pace.

The above discussion denotes that even RE sources must be conserved to balance the speed with which humans deplete and nature replaces the lost energy (the process of recharging). The modern world is facing critical challenges to maintain the consumption pace and the recharging process balanced, since:

1- Development, especially from the economic perspective, is closely tied to energy use (Toman and Jemelkova 2003, Carley, Lawrence et al. 2011, Hafezi, Akhavan et al. 2017). Although developed regions have adjusted their dependency on energy use over the past years, the outlook still suggests a net increase in total energy demand for the upcoming decades (IEA 2019, BP 2020, EIA 2020).

2- Population growth leaves the replenishment of RE sources with an increasingly difficult task. This factor is evident in human's increasing footprint, which triggers the next challenge.

3- Environmental concerns and climate change. Climate change is a natural behavior of the earth, but human manipulations stimulate changes at a sweeping pace which endanger different biological species, including humans.

Studies and statistics highlight that, during the period since 2010, we have been depleting natural resources about 20\% faster than nature can recharge them (Maczulak 2009). That means humans need more than the size of 1.2 earths to support resource consumption at the current pace (Hibbitt 2004). This chapter reviews known RE resources to delineate a comprehensive mind map about RE resources and their variations.

3. The very first RE type: the sun 
The sun is the mother of industrial era where energy resources, as the energy stored in fossil fuels, originally came from the sun.

The use of solar as an emerging energy source began in the industrial era due to the fact fossil fuels originate from the sun. Although humans cannot reproduce the crude oil forming process in an economic manner, they put forward other ways to benefit from the ultimate source of energy, the sun. Nuclear fusion reactions produce electromagnetic radiation wherein hydrogen nuclei bind to form helium, thus, releasing energy. It is informative to know that only one part of 100 total parts forms energy whereas others form the helium. This small share presents $386 \times 10^{18} \mathrm{MW}$ ( $1 \mathrm{~kg}$ TNT releases $1 \mathrm{MW}$ of power).

Sunlight is received on the earth in the form of electromagnetic radiation at the speed of light (about $300,000 \mathrm{~km} / \mathrm{s}$ ), and reflects wave form behaviors. The sun diffuses a series of electromagnetic waves with different energy contents. The energy content of a wave is related to the wavelength (i.e. peak to peak distance). The Sun's electromagnetic spectrum, presents a waves general energy content. It refers to their approximate wavelength range, which are summarized in Table 1 (Kundu, Woodgate et al. 2012, Stix 2012).

Table1. The electromagnetic spectrum

\begin{tabular}{ccc}
\hline Wave type & General energy content & Energy $(\mathrm{J})$ \\
\cline { 1 - 2 } Cosmetic & Very high & $>2 \times 10^{-14}$ \\
\cline { 1 - 2 } Gamma & High & $2 \times 10^{-17}-2 \times 10^{-14}$ \\
\hline X rays & High & $5 \times 10^{-19}-2 \times 10^{-17}$ \\
\hline Far-ultraviolet & High & $3 \times 10^{-19}-5 \times 10^{-19}$ \\
\hline Visible light & Moderately high & $2 \times 10^{-22}-3 \times 10^{-19}$ \\
\hline Near-infrared & Moderate & $2 \times 10^{-24}-2 \times 10^{-22}$ \\
\hline Far-infrared & Moderately low & $<2 \times 10^{-24}$ \\
\hline Microwave & Low & \\
\hline Television & Low & \\
\hline Radio & Very low & \\
\hline
\end{tabular}

The earth stores solar energy in chemical bonds created by photosynthetic organisms during photosynthesis. Carbon is a solar energy transfer currency. A photosynthetic organ, stores energy in an organic compound made of carbon-containing compounds. As a result, solar energy transfers up an entire food chain. However the modern world proposes new methods to exploit solar energy. Technology facilitates solar energy storage, conversion, exploration, and management such as solar photovoltaic cells (Tyagi, Rahim et al. 2013), as a device to convert light into electricity using semiconducting materials.

\section{Modern age RE resources:}

From an environmental perspective, the transition from fossil fuel burning to using RE sources lowers the total $\mathrm{CO}_{2}$ gas released into the atmosphere (Oerlemans, Sijtsma et al. 2007). Currently, the main RE types are extensively employed in the developed regions (see Table 2), primarily to produce electricity. Figure 1 compares the temporal share of worldwide RE use to other primary resources. This would appear to be a similar trend in other regions or will be followed in the future/ will follow in the future. 
It seems to be a similar trend in other regions or to be followed in the future.

Table2. RE forms of energy

\begin{tabular}{|c|c|c|c|c|c|c|}
\hline & \multirow{3}{*}{$\begin{array}{c}\text { Renewable energy } \\
\text { sources }\end{array}$} & \multicolumn{5}{|c|}{ Production } \\
\hline & & \multirow[b]{2}{*}{ Heat } & \multirow[b]{2}{*}{ Gas } & \multirow[b]{2}{*}{ Electricity } & \multirow{2}{*}{$\begin{array}{c}\text { Power } \\
\text { (mostly in } \\
\text { mechanical form) }\end{array}$} & \multirow[b]{2}{*}{ Motion } \\
\hline & & & & & & \\
\hline \multirow{3}{*}{$\begin{array}{c}\text { Ancient } \\
\text { Technologies }\end{array}$} & Water & & & & $P$ & $P$ \\
\hline & Wind & & & & $P$ & $P$ \\
\hline & Kinetic Energy & & & & $P$ & $P$ \\
\hline \multirow{5}{*}{$\begin{array}{c}\text { Today's } \\
\text { Energy } \\
\text { Technologies }\end{array}$} & Biomass & $P$ & $P$ & & & \\
\hline & Hydropower & & & $P$ & & \\
\hline & Wind & & & $P$ & & \\
\hline & Geothermal & $P$ & & $P$ & & \\
\hline & Solar & $P$ & & $P$ & & \\
\hline \multirow{2}{*}{$\begin{array}{c}\text { Emerging } \\
\text { Technologies }\end{array}$} & Hydrogen Fuel & & & & $P$ & \\
\hline & $\begin{array}{c}\text { Nanotechnology based } \\
\text { REs }\end{array}$ & & & $P$ & & \\
\hline
\end{tabular}

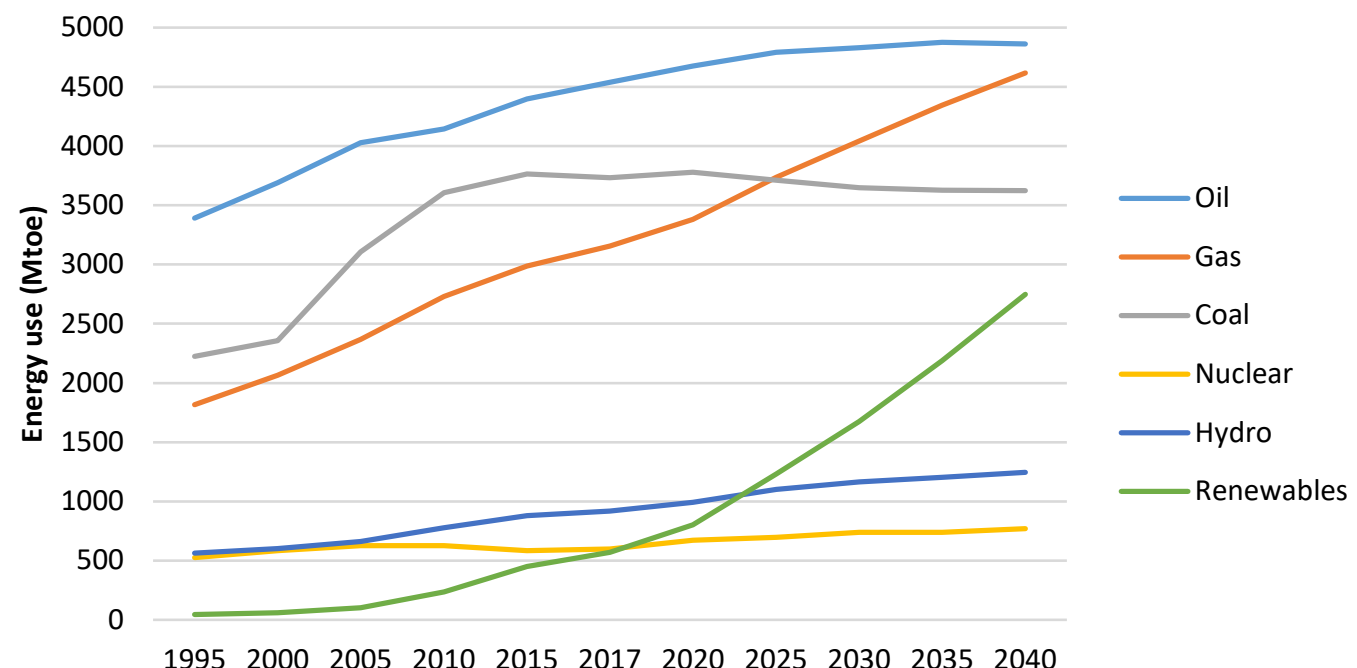

Figure1. Share of energy resources of the world's energy use (BP 2020)

REs hold strong promise for $\mathrm{CO}_{2}$ emission challenges (Alipour, Hafezi et al. 2019, Bekun, Alola et al. 2019). Of the main types of REs, only biomass releases $\mathrm{CO}_{2}$ gas into the air in the power generation process. For the best benefit of environmental conservation, burning biomass is the right choice only if its burning rate does not exceed the new plant growth rate.

Besides many hypothetical advantages, most RE resources in practice cannot produce usable energy directly, and technology is essential to convert various types of energies to each other. For instance, in a wind turbine, wind energy turns a turbine to generate electricity. Then, a neglected challenge is the technology footprint. Although solar energy is a clean type of energy, its corresponding conversion technology may have produced enormous $\mathrm{CO}_{2}$ volume or even used a lot of freshwater during the technology development processes. To approach the best 
solution, a systemic view can shed light upon the trade offs between the alternatives while investigating multiple dimensions.

\subsection{Solar power:}

The key player in the inevitable renewable energy transition is solar energy technology, in what is called 'the single largest source of additional expansion potential' (IEA 2019). As the widely available and clean form of renewable resources, solar power is the conversion of sunlight into usable energy forms, potentially able to deliver enough energy to meet the world's annual use requirements (over 14,391 in 2018) every 50 minutes (Enerdata 2019). Solar energy technologies harness radiant sunlight and heat for electricity generation and heat generation. The everevolving technologies that exploit the energy from the Sun comprise the well-established solar photovoltaics (PV) and solar thermal alongside the new emerging systems, such as artificial photosynthesis and solar architecture (Munari Probst, Roecker et al. 2013).

Solar technologies are classified as active solar and passive solar. The former spans a wide range of PV and thermal systems. The latter refers to the design and structure of the building and material selection (such as a wall, window and floor) aimed at absorbing, trapping, reflecting and distributing the solar radiation without using any external mechanical devices (Chan, Riffat et al. 2010). Up to now, much of the attention has been drawn to active solar technologies. Of the range of active solar technologies, $\mathrm{PV}$ is the most common and widely recognized technology that converts sunlight into electricity through the panels made of semiconductor cells.

The flexible PV system comes in a wide variety of forms: residential rooftop systems, solar farms, concentrating solar power systems, street lighting, public utility buildings and floating systems. Compared to other forms of renewables, the benefits of solar energy -harnessed by PV- are not limited to only one sector since it can flourish in businesses, cities, homes, industries, transportation and the commercial sector (Alipour, Hafezi et al. 2019). Since 2010, electricity generated from PV grew 22 times, from 32 TWh to a 697 TWh in 2019. At this rate, electricity from solar PV will be 2732 TWh in 2030, which meets the long-term sustainable development scenario (IEA 2019). In the next five years, the capacity of PV systems is forecasted to expand by $50 \%$ to $1200 \mathrm{GW}$ (Birol 2018). However, despite the positive effect of PV systems on the environment, there are some toxic chemicals and materials involved in the manufacture of PV (EIA 2019).

Solar thermal (heat) technology symbolizes another form of active solar technology, which harnesses the heat from sunlight. Classified by their operating temperature (low, medium and high) and by their operating principle (as nonconcentrating or concentrating), solar thermal collectors are utilized in industry, trade, agriculture, domestic, and commercial sectors. Most of the non-concentrating collectors installed worldwide are low-temperature operators $\left(<100^{\circ} \mathrm{C}\right)$ and are designed to supply space and/or water heating to buildings. A medium-temperature solar thermal system is the least common application, which works in a range of $80-250^{\circ} \mathrm{C}$ (Bhusal, Hassanzadeh et al. 2020). Some examples include solar cooling (Winston, Jiang et al. 2014), thermal desalination (Guo, Ali et al. 2016) and food processing (Milczarek, Ferry et al. 2017). High-temperature $\left(300^{\circ} \mathrm{C}>\right)$ systems require substantial capital investment and produce high-grade steam utilized in steam generators (Widyolar, Jiang et al. 2018).

Whether using solar energy for heat or electricity generation, the efficiency of all solar systems ultimately relies upon solar radiation. The amount of solar radiation depends on time, weather, the season of the year, geographical location (and subsequently, shading areas) and weather conditions. This inevitable, but pronounced, implication of solar energy suggests nonlinear or variability of the generated electricity or heat.

\subsection{Wind power:}


Wind is produced by the heating of the earth's surface (by the sun). The absorption rate of the sun's heat varies significantly as the surface of the earth is made of different textures, such as land and water. This phenomenon is called uneven heating, which empowers wind cycles. As a result, the wind is a kind of solar energy (Singh, Pant et al. 2013).

Wind is a clean, non-polluting energy resource which is both renewable and inexhaustible. A wind turbine converts kinetic wind energy to mechanical power that can be used directly, for example for pumping water, or to be used by a generator to produce electricity.

From the financial perspective, wind energy technologies require higher initial capital outlay than technologies using fossil fuels. Approximately $4 / 5$ costs are related to machinery, site preparation and installation. However, wind energy retains a strong competitive edge on a life cycle basis due largely to zero fuel prices and low operational expenses.

There are specific environmental challenges and hazards associated with construction, operation and maintenance of wind turbines:

1- Noise pollution (by the rotor blades) (Rogers, Manwell et al. 2006, Oerlemans, Sijtsma et al. 2007),

2- visual pollution (Koeppl 1982, Dhar, Naeth et al. 2019),

3- land use (Koeppl 1982, Fernández-Bellon, Wilson et al. 2019), and

4- avian mortality (caused by flying into the rotor) (Miller, Boal et al. 2008, Chang, Nielsen et al. 2013).

However, these problems are resolved in many cases by proper plant allocation (Alipour, Alighaleh et al. 2017) and through technological developments.

The most challenging aspect of wind energy exploitation is that the variable and feasible wind sites are likely to be located far from high electricity demand areas. Land use also remains a critical issue for wind farms, even though turbines can be located on lands used for grazing or farming (Brown 2001, He 2015).

\subsection{Hydropower:}

Hydropower is a kind of RE which provides the highest share of today's total RE energy production (4,200 TWh in 2018) (association 2019). Hydroelectric power plants have some competitive differences, such as:

- they do not use the resource to generate electricity,

- they barely almost do not pollute the air, water or land, as other RE plants may do (producing dams, generators and other facilities to support a hydro plant may cause environmental implications),

- they have a relatively long lifecycle to other forms of generation (100 years on average) (NREL 2003), and

- they can support rapid response to quick or unpredicted changes, but in the range for which they are designed.

Hydroelectric powerplants have played a significant role in developing the world's electric power supply, where other modern RE types are less developed. The main materials of hydroelectric power plants are water and gravity. When water falls by the force of gravity through a turbine, potential energy is transformed to mechanical work, turbines turn, and electricity is generated. Hydroelectric powerplants supplied about $40 \%$ of the total U.S. electricity in the 1920s (Wood and Sreckovic 2013). While new RE plants have developed at a faster rate (see statistics provided by International Energy Agency (IEA) such as (IEA 2019)), still hydroelectric powerplants are significant for the future. Energy outlooks forecast growth in electricity demand as both the population increases and the electricity use per person rises (BP 2020, EIA 2020).

Worldwide, hydropower continues to be a major contributor to the power grids (IEA 2019) since it can help to manage varying loads or system noises. Modern RE resource types fail to respond to such challenges and even other 
classic electricity generation technologies, such as nuclear processes and steam systems, cannot respond quickly to changes in demand. Among various powerplants, hydroelectricity is the most efficient at about 90\% (NREL 2003). On the other hand, hydropower sites extensively impact the local population: it is estimated that 30-60 million people worldwide have relocated to make way for hydropower plants (Bhatia 2014). Additionally, dams sometimes must be destroyed. Dams have a long lifecycle, and it can be claimed that about $1 \%$ of each will collapse at some time in its life. Similar to nuclear power plants, in a hydroelectric plant, the risk of a major catastrophe is minimal, while consequences can be disastrous. As a potential solution, one may propose to develop a small number of large reservoirs instead of a large number of small ones. Small reservoirs tend to be more acceptable to the public; and similarly, from the energy security and grid management perspective, small reservoirs prove to be more feasible.

The economic profitability of hydropower energy heavily depends on how future costs are discounted like other large infrastructure projects. There is another cost arising at the end of the effective life of the dam, as the basis of a hydroelectric power plant. This problem resembles the decommissioning stage of nuclear power plant management, leaving the question of whom should pay such costs? As noted earlier, the life cycle operation costs of a hydroelectric power plant are low since the required resources are free. Its lifecycle period is also literally long (about 100 years on average); however, efficiency declines with the increasing lifespan, due to the sedimentation. Consequently, most hydroelectric power plants are funded by governments, rather than private sectors (a similar claim has been made by (Uria-Martinez, Johnson et al. 2018)). With the relatively cheap fossil fuels and the development of a hydroelectric power plants being limited to the existence of water, the share of hydroelectric electricity has remained stagnant in the energy baskets of countries (for example see data provided by (EIA 2020)). Nevertheless, it is a source of low carbon energy supply and is known to a low carbon future.

\subsection{Wave and tidal power:}

\subsubsection{Tidal power:}

Tidal mills are the first cases of using tidal force to turn a stone mill to grind corn. The tidal basin is used to generate electricity through two different types of turbines, conventional ones that are efficient but operate while water flows in one direction, and turbines that can operate in both directions. Broadly, tidal power plants have vague, long-range ecological and environmental effects within the location of its implementation. Several small tidal power plants have been deployed recently to gain operational experiences and to study the side effects. However, efforts to build a tidal power plant on the River Severn in the UK failed mainly due to five reasons:

1- Large construction costs,

2- public disagreements,

3- availability of more economical alternatives,

4- distribution network problems due to long geographical distance between plant and consumer, and

5- the power plant being threatened by devastating marine storms.

Tidal power is the only energy source, which does not fit into the earth-sun system while other natural energies originate directly or indirectly from the sun.

Like wind energy, the location is crucial to tidal power plants: they need to be placed in areas with fast currents, such as around rocky points or at the entrance to rivers. Like other RE types, tidal energy is emission free, which offers some benefits compared to using conventional fossil fuels. In addition, tidal power is predictable with a high energy density (seawater is 832 times as dense as air (Chettiar, Narayan et al. 2015)), and consequently, has more power supply capacity. Without considering financial aspects, some environmental impacts are associated with tidal power plant systems arising from:

1- Interruption of aquatic migration routes, 
2- destruction of the ecosystem of organisms, and

3- potential of acoustic pollutions.

\subsubsection{Wave energy:}

The origin of sea surface waves is most commonly wind and can be considered as solar energy. When winds pass the sea surface, their energy transfers to the water as waves. Technologies for wave power are not used extensively when compared to other RE versions, such as solar power, wind power and hydropower. Since 1890, there have been attempts to employ this power (Miller 2004), referring to high power density. The global potential of wave power is immense (McCormick 2013, Bhatia 2014), about 500-gigawatt electrical energy (GWe) with $2 \%$ of the world's coastline (referring to 2014 estimation) (IRENA 2014). From the environmental viewpoint, wave power is clean energy and produces no greenhouse gases, regardless of the emissions from technology development processes. Unlike shore-based sites, such as for tidal power plants, wave power plants do not cause visual pollution.

Ocean current is a continuous movement of seawater created via wind, salinity, temperature and so on. Ocean current energy is distinct from tidal and waves powers. Yet, ocean current energy-related technologies are in their early developmental stages (Lee, Lee et al. 2010), so positive and negative characteristics are not obvious (Joseph 2013, McCormick 2013, Neumann 2014).

\subsection{Geothermal:}

Geothermal energy comes from the trapped heat energy inside the earth. Traditionally harnessed for heating purposes, generating electricity from geothermal has increasingly become a viable option. Geothermal energy exists inside the earth and can be found in three forms (Bhatia 2014): (1) volcanoes, (2) hot springs, and (3) geysers. Geothermal energy can be reproduced by the earth over time, so it is known as a RE resource but not inexhaustible in the same way as solar energy. Moreover, it is a sustainable energy option since it is clean and environmentally friendly. Various claims have been made about the potentials of geothermal energy by putting forward how they can contribute to the world's energy demand (Tabak 2009). The future of such a kind of energy critically depends on supply volume and competitive features of the energy compared to other RE resources based on financial, technology availability and reliability. As with other renewables, the supply of the geothermal energy is restricted to specific geographies, which increases transmission costs of this type. From the economic perspective, the size of the plant specifies the needed scale of investment and resource potential. However, as with other RE technologies, economies of scale may introduce efficiencies which affect the economic characteristics of a geothermal power plant.

Besides construction, operation and maintenance costs of a geothermal power plant, other challenges include:

1- Transmission challenges: the heat cannot be transported over a few miles without heat loss, so the plants must be developed near or even at the reservoir site. Then power transmission lines must be developed to access the local grid.

2- Reservoir capacity uncertainty: since estimating the reservoir capacity along with risks, it is costly to overuse resources. A rational solution is to develop a small plant then gently expand its capacity.

Generally, larger plants face more social opposition and introduce more environmental dimensions/risks. Incentives, such as tax credits and government-guaranteed prices, are used to encourage private investors. However, small size plants may be preferred to larger ones because risks and costs can be controlled better.

Although geothermal power plants are environmentally friendly, the technology must address concerns around:

1- Noise controlling, 
2- visual impacts and pollutions,

3- adverse effects on vegetation and animal habitats around the site (biological effects),

4- monitoring and maintenance activities,

5- fluid withdrawal and thermal effects, and

6- possibility of chemical pollutions.

\subsection{Nuclear fission and fusion:}

Among all known energy sources, nuclear energy supplies the most power for a unit of fuel (Maczulak 2009). One kilogram of uranium approximately provides power equivalent to 42 gallons of oil, 1 ton of coal, or 17,000 cubic feet of natural gas (Zohuri 2015). But there is strong opposition to the development of nuclear power plants due to the risk of radioactive accidents. Recent examples include: the leak of radioactive materials from the Waste Isolation Pilot Plant (WIPP) in New Mexico, U.S. (Nelson, Patterson et al. 2015, lalenti 2018); and disaster, such as the Mayapuri radiation accident (Bagla 2010), Fukushima nuclear accident (Holt, Campbell et al. 2012, Shigemura, Tanigawa et al. 2012) and Chernobyl disaster (Marples 1988, Berger 2010).

Nuclear energy is extracted via fission and fusion processes. In fission, heavy atoms are broken to form new lighter ones, releasing neutrons and energy. The neutrons crash into other heavy atoms, breaking them to release more energy and neutrons. Nuclear fission is sustained through a chain reaction which releases an enormous amount of energy. The fission of $1 \mathrm{~g}$ of uranium or plutonium is equivalent to about 600 gallons of oil/ 3 tons of coal (Masterson 2017).

Conversely, the fusion process merges two atoms at a high temperature and under high force to form a new heavy nucleus. This process releases a great amount of energy (Maczulak 2009). To create a better image, note that fusion releases 3.6 megaelectronvolt, while fission releases 0.85 megaelectronvolt on a per nucleon basis (Haider 2019).

The energy released during nuclear fission is used to generate steam to generate electricity. The Nuclear Energy Institute proposed that it can be a suitable power source for plug-in electric vehicles (McPharlin 2020). Despite claims that nuclear energy will limit fossil fuel use in transport, its use is expected to be limited to shipping in the short term.

Nuclear energy is a promising alternative to replacing coal and crude oil. However, nuclear disasters although less likely to occur, have irreparable environmental consequences. Consequently, some European countries have restricted their nuclear power plant development programs. For example, following the Fukushima nuclear accident, the German government passed a bill to phase-out the nuclear energy (Luh 2014, Schiffer and Trüby 2018, IEA 2020). Moreover, countries that have knowledge and technology of nuclear power generation can also produce atomic bombs, which is a global threat to humanity.

Another challenge is land use (Takahashi, Tamura et al. 2015). Exploiting the land surrounding a nuclear power plant is challenging owing to nuclear radiation concerns, and that there is no tested mechanism for clearing the site for public use. Similarly, waste management is another concern. Decommissioning nuclear power is uncertain, both for technological and economic reasons. The main advantages of nuclear energy comprise:

1- Steady energy generation,

2- low emissions,

3- matured and available technology, and

4- not utilizing a lot of land because these power plants can supply lots of electricity.

The disadvantages of nuclear energy include:

1- Costs of the operation,

2- possibility of a broad level disaster, 
3- nuclear waste management challenges,

4- nuclear radiation,

5- need for strict and vigilant monitoring and security, and

6- endangering the ecology, around nuclear sites, since a nuclear power plant releases hot process water into the environment.

Nuclear energy may be classified under the non-RE category because it uses uranium, which is a non-renewable element. However, some scientists argue that it is renewable since a nuclear reaction is a self-sustaining process (Maczulak 2009).

\subsection{Biomass and biofuels:}

Biomass stores energy in the form of chemical bonds of carbohydrates, fats and proteins present in all living things in a food chain. Unlike other RE types, biomass is mostly used to supply energy via the earth's nutrient recycling. As an energy type, biomass is developed in biofuel's shadow (Maczulak 2009).

Agricultural wastes, landfills, and municipal solid waste, and wood are various types of solid biomass (McKendry 2002, McKendry 2002, Santanu, Avinash et al. 2018). Biomass may be used in its natural form, such as wood and crop waste, or converted to other fuels, such as ethanol, biodiesel and biogas. Biofuels generally contain more energy than biomass, but biomass mostly charge less, in term of costs.

Ethanol (Ethyl Alcohol) is the leading biofuel used today. Ethanol is utilized as a motor fuel, and most petrol vehicles in service can use blends of ethanol (up to $10 \%$ ). However, biofuels can lead to:

1- Increased prices for crops as feedstock for biofuels may cause food shortage, and

2- threats to habitat and biodiversity.

Biodiesels are produced using plant sources instead of crude oil, and supply about 2.5 times the energy compared to an equal amount of fossil fuel (Maczulak 2009, Shirvani, Yan et al. 2011). Algae is an emerging alternative energy source that can address the disadvantages of growing fuel crops. However, producing algae-based energy requires diligent research and development programs. (Sander and Murthy 2010, Borowitzka and Moheimani 2013, Borowitzka, Moheimani et al. 2013, Pandey, Lee et al. 2013) Therefore, it is necessary to provide sufficient information about algae energy production methods, technologies, and protocols.

\section{Carbon economics:}

Carbon is the sixth most abundant element on earth representing less than $0.1 \%$ of the earth's crust (Maczulak 2009). The carbon formed life and living things on earth. As a result, it is the main element of fossil fuels, such as coal, oil, and natural gas. The carbon cycle maintains a natural balance of carbon on the earth, sea and the atmosphere. However, the carbon dioxide $\left(\mathrm{CO}_{2}\right)$ emissions caused by burning fossil fuels exceed the assimilative capacity of land and sea. This implication leads to an accumulation of the gas in the atmosphere that disturbs the balance and endangers the environment. The $\mathrm{CO}_{2}$ and methane $\left(\mathrm{CH}_{4}\right)$ are known as greenhouse gases that play a central role in climate change. Moreover, carbon combines with other elements to form acids, leading to acid rain. Carbonic acid $\left(\mathrm{H}_{2} \mathrm{CO}_{3}\right)$ is a weak acid and rarely causes true acid rains, but the more $\mathrm{CO}_{2}$ added to the atmosphere, the more carbonic acid comes down with the rainwater. Acid rain damages trees, human, and animal health, and even changes oceans' chemical conditions to a limited extent. Carbon economics is defined as tracking both beneficial (as energy and life source) and harmful forms of carbon (as an element of greenhouse gases). The notion aims to facilitate world carbon trading through buying and selling carbon units, called carbon offset, via the international market. In this market, entities emitting less than an agreed level of $\mathrm{CO}_{2}$ receive credits which can be 
sold to entities that emit over the amount permitted. That is, polluters should pay a fee as a penalty for the difference of permitted value and over.

The Kyoto Protocol announced carbon trading as a benefit to the environment. However, questions remain about such an emerging energy-related market (Kollmuss, Zink et al. 2008, Böhm 2009, Kollmuss, Lazarus et al. 2010, Lovell and Liverman 2010, Brohé, Eyre et al. 2012). A certain fact is, REs support and promote low carbon policies.

\section{Smart energy grids:}

An energy grid is a large distribution network designed to carry electricity or natural gas from suppliers to users. A country may have an extensive, central grid connected to smaller local grids. For example, Iran's natural gas grid has thousands of kilometers of pipeline to distribute natural gas across the country (Hafezi, Akhavan et al. 2017, Hafezi, Akhavan et al. 2019).

In the case of power grids, conventional networks are used to transmit high-voltage electricity unidirectionally from produces to consumers. Hydroelectric power plants, gas power plants, nuclear power plants, and coal-fired power stations accounted for about $90 \%$ in 2017 (IEA 2019) of electricity supply. Although such networks have worked well, about $5 \%$ of energy is wasted during the transmission and distribution to the end user in the U.S. (refereeing to the U.S. Energy Information Administration (EIA) estimations).

On the other hand, smart energy grids propose a bidirectional grid, which encourage the use of alternative power sources, mostly based on small distributed RE generators. Such small plants can be fostered by private sectors or even households or businesses at the end user level, unlike most conventional, large-scale power plants. Governments follow free energy market policies, or consider energy subsidies for regional power generation to encourage private sector participation. The introduction of smart grids has three outcomes:

1. The change in network operation and user participation in smart grids may lead to the elimination of some parts of conventional power grids,

2. smart grids can offer a higher energy security level (for more information about energy security see "energy security and sustainable development" (Alipour, Hafezi et al. 2018)), and

3. the two-way flow procedure of the smart grid minimizes wastes, which mean higher efficiency, lower price, adjusted energy intensity, and indirectly supporting social justice.

Figure 2 shows the smart grid transactions, actors, and characteristics in a simple way.

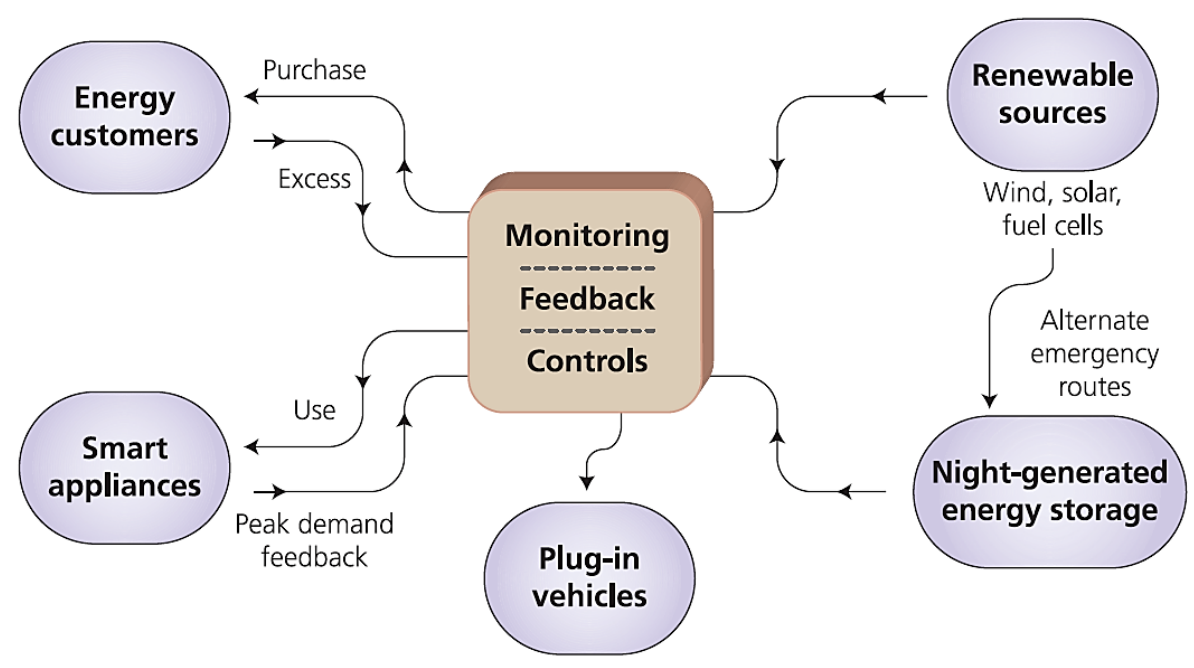

Figure2. Characteristics of a smart energy grid (Maczulak 2009) 
A smart grid needs monitoring systems to manage the electricity usage continuously. The two-way property of a smart grid provides feedbacks that supports responsibility, diagnosis and system adaptability. Currently, China is planning to adopt its electricity supply with smart grids, and European countries have also made investments in smart systems (Maczulak 2009).

\section{Alternative energies and society:}

The role of society in the promotion of RE technologies can be delineated by two perspectives. The first viewpoint invokes the deployment of RE sources at utility-scale, such as solar farms and wind farms and other grid-connected renewables. In some cases, the end user supports the deployment of these RE systems through paying more for electricity to cover the difference between the cost of generating electricity from fossil fuel and RE sources. This involvement may render two reverberations: first, increasing the knowledge and direct contribution of the end user towards the deployment of the REs; and second, more energy efficiency and consumption measures when realizing the grid electricity is generated from REs.

The second and more pervasive view refers to the direct acquisition, adoption, and utilization of small-scale RE technologies by the household. Small-scale REs are known as 'distributed' or 'behind the meter' technologies since they are often smaller generation units located on the consumer's side of the meter. A non-prejudiced individual commonly takes seven major considerations into account before deciding to adopt a RE technology (Figure 3). Technically, incorporating and operationalizing many of the renewables, such as solar, wind, biomass and geothermal, into building designs is conceivable. In practice, technologies may neither be economically feasible nor meet the physical conditions of the building. Of the four resources, rooftop solar PV and solar thermal are the most likely small-scale electricity generators for future energy-autonomous domestic customers and offer several advantages: abundant solar is easily accessible, PV does not compete for space as it can be installed on the rooftop, the technology is and has achieved grid parity in some locations and is applicable to off-grid applications in remote areas. The utilization of solar systems may also satisfy the environmental and personal values of the individuals.

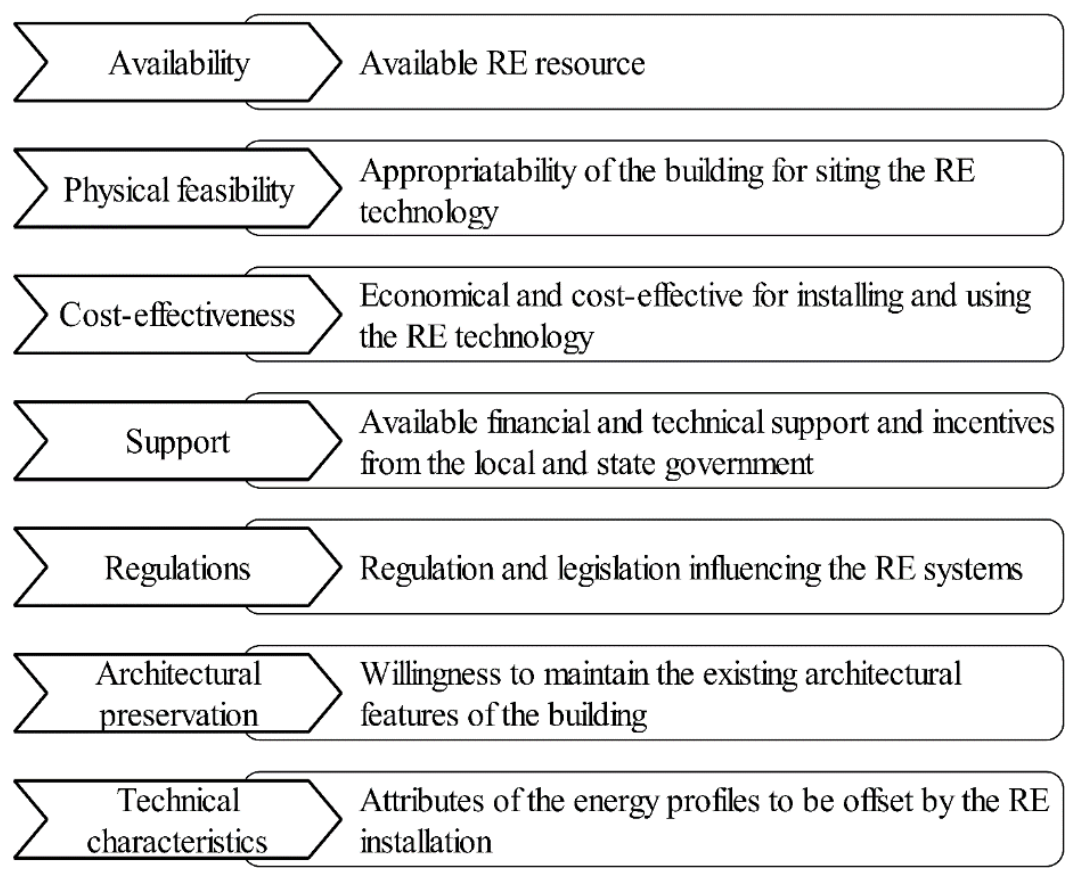

Figure3. Seven major considerations of RE installations by the residential sector 
Accordingly, local and state governments have long adopted various forms of incentive mechanisms to promote the adoption of distributed REs. These include rebates, grants, tax exemptions, Feed-in Tariff (FiT) schemes, interest-free loans and changing the existing regulations. However, success or failure in these deployment policies ultimately depends on the householder's decision to accept or reject the technology. They are the main actor in the uptake decision-making process and, as such, decide whether and to what extent any considered deployment policies will translate into success. At the same time, households' decisions are bounded rational, and their final behavior to accept and adopt the technology relies upon several endogenous and exogenous determinants, which makes understanding and predicting complex. At the sociodemographic level, income, age, gender and employment often have a direct correlation with the decision (Sardianou and Genoudi 2013).

The characteristics of the house play a significant role in the decision and involve both the physical and nonphysical features. Some examples of physical characteristics include house size, house type and roof type. Non-physical characteristics can be: geographical location, house value (which is a proxy for the affordability of the person), and ownership. The attributes of the building unfold the technical feasibility of installation, economic aspects and affordability of the purchase. Before deciding to install a small-scale RE system, households evaluate the financial and technical features of the technology. They acquire this information from formal and informal channels: formal comprises government, business, supplier; while informal channels include peers and the media. At the individual level, psychological factors shape the attitude and the personality highlighting the extent to which a person is novelty seeking. It also denotes environmental and personal values and his/her perceived risks of using the technology. The final decision to uptake and consume a RE resource is usually made by the formation of all these predictors (Alipour, Salim et al. 2020).

\section{Discussion:}

The REs are known as clean energy sources, but how clean are they? Pehl et al. (2017) have studied life-cycle emissions of future low-carbon power supply systems and implications for technology choice. They made predictions to 2050 and have showed the life-cycle emissions from fossil fuel carbon capture and sequestration plants of 78-110 gCO2eq kWh-1, compared with 3.5-12 gCO2eq kWh-1 for nuclear, wind and solar power (Pehl, Arvesen et al. 2017). More details are provided in figure 4 and 5, which are designed to present embodied energy use of electricity production, and greenhouse gas (GHG) emissions.

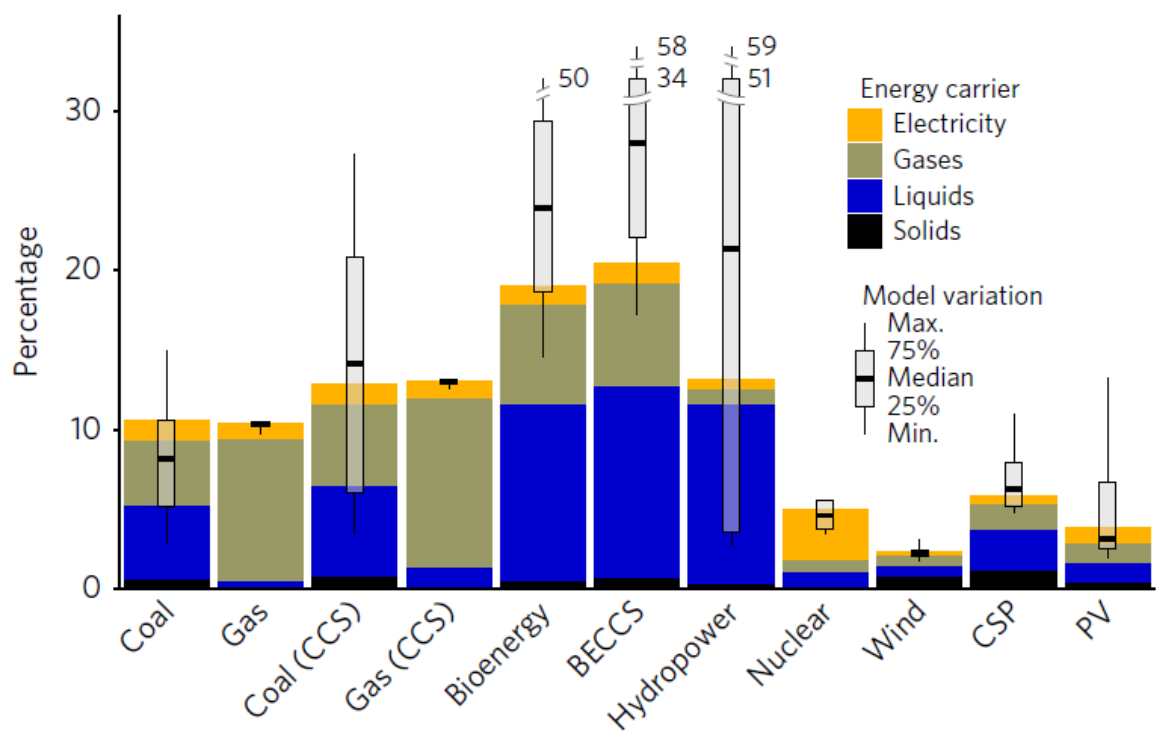

Figure4. Embodied energy use of electricity production as a percentage of lifetime electricity production. Global average values are shown by secondary energy carrier (colored bars) for capacities built in 2050. Combined model variations over both regions and technology variants are shown as grey boxplots (Pehl, Arvesen et al. 2017). 


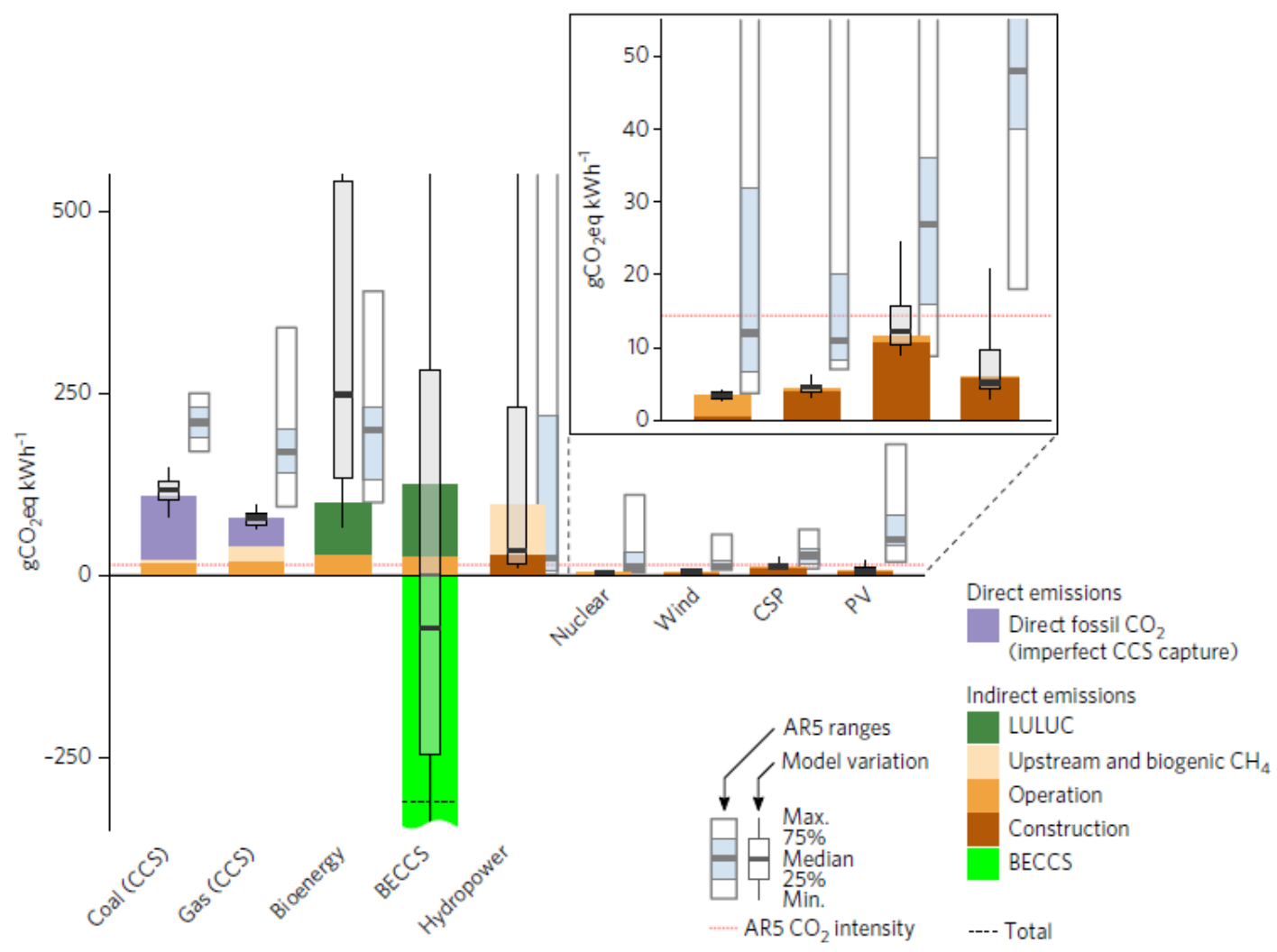

Figure5. Specific direct and indirect GHG emissions. Global 2050 average of lifetime emissions over lifetime electricity production (solid colored bars), for capacities built in 2050 in a $2{ }^{\circ} \mathrm{C}$-consistent mitigation scenario. Model variations across both regions and technology variants are shown as boxplots. (Pehl, Arvesen et al. 2017).

Although the share of REs in the global energy market is set to increase (it is estimated that in 2040 Renewable electricity generation will increase 2.5 times referring to 2018*) (IEA 2019, BP 2020, EIA 2020), challenges remain which may profoundly affect their contributions. Governments are at the forefront of developing RE deployment policies. Some major challenges involve:

1- Lack of risk awareness; some RE resource types are less developed (such as nuclear fusion), and various dimensions of their environmental damages are unclear, such as noise pollution and the destruction of plant and animal habitats. Moreover, most RE resources have variable output, which affects their electricity generation potential,

2- power grid stability; the stability of the conventional grids is threatened by RE resources (Eftekharnejad, Vittal et al. 2012, Shah, Mithulananthan et al. 2015). Smart grids are challenging as the two-way electricity flow may put electricity supplies at risk, since power supply capacity is not stable and it challenges the ability to guarantee quick response,

3- false carbon credits; the carbon footprint of alternative and RE resources is not always obvious, especially in the case of biofuels. Moreover, producing RE related equipment and technologies may release greenhouse gases and increase $\mathrm{CO}_{2}$ pollution, and

4- the RE-water-food nexus; RE water usage both in terms of use to produce equipment and electricity generation process. Biofuels can threaten food supply and put the world at food poverty risk (Fischer, Hizsnyik et al. 2009, Koizumi and Reviews 2015). The issue of power supply should not aggravate water security. Accordingly, a sustainable future energy supply system will keep the energy-water-food cycle in balance.

\footnotetext{
* IEA, "Renewable electricity generation by region and scenario, 2018-2040", IEA, Paris https://www.iea.org/data-andstatistics/charts/renewable-electricity-generation-by-region-and-scenario-2018-2040
} 
In summary, our world needs immediate action: however, the response to modern days' emerging concerns must be supported by science, accepted by the public and be in line with an executive commitment by governments.

\section{Cross-References}

Energy Management and Sustainable Development; Energy Security and Sustainable Development.

\section{References}

Alipour, M., S. Alighaleh, R. Hafezi and M. J. E. Omranievardi (2017). "A new hybrid decision framework for prioritizing funding allocation to Iran's energy sector." 121: 388-402.

Alipour, M., R. Hafezi, B. Ervural, M. A. Kaviani and Ö. J. E. Kabak (2018). "Long-term policy evaluation: Application of a new robust decision framework for Iran's energy exports security." 157: 914-931.

Alipour, M., R. Hafezi, E. Papageorgiou, M. Hafezi and M. Alipour (2019). "Characteristics and scenarios of solar energy development in Iran: Fuzzy cognitive map-based approach." Renewable and Sustainable Energy Reviews 116: 109410.

Alipour, M., R. Hafezi, E. Papageorgiou, M. Hafezi, M. J. R. Alipour and S. E. Reviews (2019). "Characteristics and scenarios of solar energy development in Iran: Fuzzy cognitive map-based approach." 116: 109410.

Alipour, M., H. Salim, R. A. Stewart and O. Sahin (2020). "Predictors, taxonomy of predictors, and correlations of predictors with the decision behaviour of residential solar photovoltaics adoption: A review." Renewable and Sustainable Energy Reviews 123: 109749.

association, I. h. (2019). 2019 Hydropower Status Report.

Bagla, P. (2010). Radiation accident a 'wake-up call'for India's scientific community, American Association for the Advancement of Science.

Bekun, F. V., A. A. Alola and S. A. J. S. o. t. T. E. Sarkodie (2019). "Toward a sustainable environment: Nexus between CO2 emissions, resource rent, renewable and nonrenewable energy in 16-EU countries." 657: 1023-1029.

Berger, E. M. J. K. (2010). "The Chernobyl disaster, concern about the environment, and life satisfaction." 63(1): 18.

Bhatia, S. (2014). Advanced renewable energy systems,(Part 1 and 2), WPI Publishing.

Bhusal, Y., A. Hassanzadeh, L. Jiang and R. Winston (2020). "Technical and economic analysis of a novel low-cost concentrated medium-temperature solar collector." Renewable Energy 146: 968-985.

Birol, F. (2018). Renewables 2018: market analysis and forecast from 2018 to 2023. IEA.

Böhm, S. (2009). Upsetting the offset: the political economy of carbon markets, London: MayFlyBooks, 2009.

Borowitzka, M. A. and N. R. Moheimani (2013). Algae for biofuels and energy, Springer.

Borowitzka, M. A., N. R. J. M. Moheimani and A. S. f. G. Change (2013). "Sustainable biofuels from algae." 18(1): 13-25.

BP (2020). Energy Outlook. London, United Kingdom, British Petroleum.

Brohé, A., N. Eyre and N. Howarth (2012). Carbon markets: An international business guide, Routledge.

Brown, L. J. E. P. I. R. f. h. w. s. c. A. U. p. (2001). "US Farmers Double Cropping Corn and Wind Energy."

Carley, S., S. Lawrence, A. Brown, A. Nourafshan, E. J. R. Benami and S. E. Reviews (2011). "Energy-based economic development." 15(1): 282-295.

Chan, H.-Y., S. B. Riffat and J. Zhu (2010). "Review of passive solar heating and cooling technologies." Renewable and Sustainable Energy Reviews 14(2): 781-789.

Chang, T., E. Nielsen, W. Auberle and F. I. J. E. i. a. r. Solop (2013). "A quantitative method to analyze the quality of EIA information in wind energy development and avian/bat assessments." 38: 142-150.

Chettiar, N., S. Narayan, J. N. Goundar and A. Deo (2015). Design of a gorlov turbine for marine current energy extraction. Applied Mechanics and Materials, Trans Tech Publ. 
Dhar, A., M. A. Naeth, P. D. Jennings and M. G. J. S. o. T. T. E. El-Din (2019). "Perspectives On Environmental Impacts And A Land Reclamation Strategy For Solar And Wind Energy Systems." 134602.

Eftekharnejad, S., V. Vittal, G. T. Heydt, B. Keel and J. J. I. t. o. p. s. Loehr (2012). "Impact of increased penetration of photovoltaic generation on power systems." 28(2): 893-901.

EIA (2020). Annual Energy Outlook. Washington, D.C., United States, U.S. Energy Information Administration.

EIA, U. S. E. I. A. (2019). Solar explained-Solar energy and the environment, EIA, U.S. Energy Information Administration.

Enerdata (2019). Total energy consumption.

Fernández-Bellon, D., M. W. Wilson, S. Irwin and J. J. C. B. O'Halloran (2019). "Effects of development of wind energy and associated changes in land use on bird densities in upland areas." 33(2): 413-422.

Fischer, G., E. Hizsnyik, S. Prieler, M. Shah and H. van Velthuizen (2009). "Biofuels and food security."

Guo, H., H. M. Ali and A. Hassanzadeh (2016). "Simulation study of flat-sheet air gap membrane distillation modules coupled with an evaporative crystallizer for zero liquid discharge water desalination." Applied Thermal Engineering 108: 486-501.

Hafezi, R., A. Akhavan and S. Pakseresht (2017). The State of Competition in Natural gas Market Application of Porter's Five Forces for NIGC. Proceedings of the International Gas Union Research Conference (IGRC), Rio de Janeiro, Brazil.

Hafezi, R., A. Akhavan, S. J. J. o. N. G. S. Pakseresht and Engineering (2017). "Projecting plausible futures for Iranian oil and gas industries: Analyzing of historical strategies." 39: 15-27.

Hafezi, R., A. N. Akhavan and S. Pakseresht (2019). "RE: New Democratic Role for Iran in Global Energy Market."

Haider, Q. (2019). Nuclear Fusion: Holy Grail of Energy. Nuclear Fusion-One Noble Goal and a Variety of Scientific and Technological Challenges, IntechOpen.

He, W. J. W. E. (2015). "Jacket-cage: dual-use the jacket foundation of offshore wind turbine for aquaculture farming." 39(3): 311-320.

Hibbitt, C. J. (2004). External environmental disclosure and reporting by large European companies: An economic, social, and political analysis of managerial behaviour, Rozenberg Publishers.

Holt, M., R. J. Campbell and M. B. Nikitin (2012). Fukushima nuclear disaster, Congressional Research Service.

Ialenti, V. J. B. o. t. A. S. (2018). "Waste makes haste: How a campaign to speed up nuclear waste shipments shut down the WIPP long-term repository." 74(4): 262-275.

IEA (2019). Electricity Information, International Energy Agency.

IEA. (2019). "Renewables 2019; Market analysis and forecast from 2019 to 2024." Retrieved 8 November 2019, from https://www.iea.org/renewables2019/.

IEA (2020). Germany 2020. Energy Policy Review International Energy Agency.

IRENA (2014). Wave Energy. Technology Brief. Abu Dhabi, UAE, International Renewable Energy Agency.

Joseph, A. (2013). Measuring ocean currents: tools, technologies, and data, Newnes.

Koeppl, G. W. (1982). "Putnam's Power from the Wind."

Koizumi, T. J. R. and S. E. Reviews (2015). "Biofuels and food security." 52: 829-841.

Kollmuss, A., M. Lazarus, C. Lee, M. LeFranc and C. Polycarp (2010). Handbook of carbon offset programs: trading systems, funds, protocols and standards, Routledge.

Kollmuss, A., H. Zink and C. J. W. G. Polycarp (2008). "Making sense of the voluntary carbon market: A comparison of carbon offset standards." 1-23.

Kundu, M. R., B. Woodgate and E. J. Schmahl (2012). Energetic Phenomena on the Sun, Springer Science \& Business Media.

Lee, S. H., S. H. Lee, K. Jang, J. Lee and N. J. C. A. P. Hur (2010). "A numerical study for the optimal arrangement of ocean current turbine generators in the ocean current power parks." 10(2): S137-S141.

Lovell, H. and D. J. N. P. E. Liverman (2010). "Understanding carbon offset technologies." 15(2): 255-273.

Luh, D. (2014). Energy transition in Germany until 2040: what are Germany's energy options to compensate for the nuclear phase-out in 2022? , University of Twente.

Maczulak, A. E. (2009). Renewable energy: sources and methods, Infobase Publishing. 
Marples, D. R. (1988). The social impact of the Chernobyl disaster, Springer.

Masterson, R. E. (2017). Nuclear Engineering Fundamentals: A Practical Perspective, CRC Press.

McCormick, M. E. (2013). Ocean wave energy conversion, Courier Corporation.

McKendry, P. J. B. t. (2002). "Energy production from biomass (part 1): overview of biomass." 83(1): 37-46.

McKendry, P. J. B. t. (2002). "Energy production from biomass (part 2): conversion technologies." 83(1): 47-54.

McPharlin, K. (2020). "Super Bowl Ads Promise Electric Vehicles. Nuclear Can Fuel Them with Clean Energy." from https://www.nei.org/news/2020/super-bowl-ads-electric-vehicles.

Milczarek, R. R., J. J. Ferry, F. S. Alleyne, C. W. Olsen, D. A. Olson and R. Winston (2017). "Solar thermal drum drying performance of prune and tomato pomaces." Food and Bioproducts Processing 106: 53-64.

Miller, A., C. Boal, L. Nagy and B. J. P. a. t. Woeck (2008). "Estimating Avian and Bat Mortality and Identifying Spatial and Temporal Distribution at a Utility-Scale Wind Energy Development."

Miller, C. (2004). Wave and tidal energy experiments in san francisco and santa cruz, August.

Munari Probst, M. C., C. Roecker, F. Frontini, A. Scognamiglio, K. Farkas, L. Maturi and I. Zanetti (2013). Solar Energy Systems in Architecture-integration criteria and guidelines, Munari Probst, Maria Cristina and Roecker, Christian for International ....

Nelson, R., R. Patterson and A. VanLuik (2015). The February 2014 Accidents at WIPP: What Happened and What We Know about Why. WM2015 Conference.

Neumann, G. (2014). Ocean currents, Elsevier.

NREL (2003). "Hydropower. Available from: https://www.nrel.gov/docs/fy04osti/34916.pdf."

Oerlemans, S., P. Sijtsma, B. M. J. J. o. s. López and vibration (2007). "Location and quantification of noise sources on a wind turbine." 299(4-5): 869-883.

Pandey, A., D.-J. Lee, Y. Chisti and C. R. Soccol (2013). Biofuels from algae, Newnes.

Pehl, M., A. Arvesen, F. Humpenöder, A. Popp, E. G. Hertwich and G. Luderer (2017). "Understanding future emissions from low-carbon power systems by integration of life-cycle assessment and integrated energy modelling." Nature Energy 2(12): 939-945.

Rogers, A. L., J. F. Manwell and S. J. R. E. R. L. Wright, University of Massachusetts at Amherst (2006). "Wind turbine acoustic noise."

Sander, K. and G. S. J. T. I. J. o. L. C. A. Murthy (2010). "Life cycle analysis of algae biodiesel." 15(7): 704-714.

Santanu, D., K. Avinash, V. Moholkar and B. Thallada (2018). Coal and Biomass Gasification. Recent Advances and Future Challenges, Springer Nature Singapore Pte Ltd., Singapore.

Sardianou, E. and P. Genoudi (2013). "Which factors affect the willingness of consumers to adopt renewable energies?" Renewable energy 57: 1-4.

Schiffer, H.-W. and J. J. E. T. Trüby (2018). "A review of the German energy transition: taking stock, looking ahead, and drawing conclusions for the Middle East and North Africa." 2(1-2): 1-14.

Shah, R., N. Mithulananthan, R. Bansal, V. J. R. Ramachandaramurthy and S. E. Reviews (2015). "A review of key power system stability challenges for large-scale PV integration." 41: 1423-1436.

Shigemura, J., T. Tanigawa, I. Saito and S. J. J. Nomura (2012). "Psychological distress in workers at the Fukushima nuclear power plants." 308(7): 667-669.

Shirvani, T., X. Yan, O. R. Inderwildi, P. P. Edwards, D. A. J. E. King and E. Science (2011). "Life cycle energy and greenhouse gas analysis for algae-derived biodiesel." 4(10): 3773-3778.

Singh, A., D. Pant and S. I. Olsen (2013). Life cycle assessment of renewable energy sources, Springer.

Stix, M. (2012). The Sun: an introduction, Springer Science \& Business Media.

Tabak, J. (2009). Solar and geothermal energy, Infobase Publishing.

Takahashi, J., K. Tamura, T. Suda, R. Matsumura and Y. J. J. o. e. r. Onda (2015). "Vertical distribution and temporal changes of 137 Cs in soil profiles under various land uses after the Fukushima Dai-ichi Nuclear Power Plant accident." 139: 351-361.

Toman, M. T. and B. J. T. E. J. Jemelkova (2003). "Energy and economic development: an assessment of the state of knowledge." 24(4). 
Tyagi, V., N. A. Rahim, N. A. Rahim, A. Jeyraj, L. J. R. Selvaraj and s. e. reviews (2013). "Progress in solar PV technology: Research and achievement." 20: 443-461.

Uria-Martinez, R., M. Johnson and P. O'Connor (2018). 2017 Hydropower Market Report Highlights, Oak Ridge National Lab.(ORNL), Oak Ridge, TN (United States).

Widyolar, B., L. Jiang and R. Winston (2018). "Spectral beam splitting in hybrid PV/T parabolic trough systems for power generation." Applied Energy 209: 236-250.

Winston, R., L. Jiang and B. Widyolar (2014). "Performance of a $23 \mathrm{KW}$ solar thermal cooling system employing a double effect absorption chiller and thermodynamically efficient non-tracking concentrators." Energy Procedia 48(1): 1036-1046.

Wood, A. and G. Sreckovic (2013). "The Sustainability of Pacific Northwest Hydropower Generation in the Context of Nonstationarity and Renewable Energy Growth."

Wrigley, E. A. (2010). Energy and the English industrial revolution, Cambridge University Press.

Zohuri, B. (2015). Application of compact heat exchangers for combined cycle driven efficiency in next generation

nuclear power plants: a novel approach, Springer. 